\title{
BOR DERGISI

\section{The effect of high boron additions on the microstructure of cast steel}

\author{
Ömer Faruk Murathan ${ }^{1 *}$, Kadir Kocatepe ${ }^{2}$, Mehmet Erdoğan ${ }^{3}$ \\ ${ }^{1}$ Gazi University, Faculty of Technology, Deparment of Metallurgical and Materials Engineering, Ankara, Turkey, \\ ORCID ID orcid.org/0000-0002-3636-2164 \\ ${ }^{2}$ Gazi University, Faculty of Technology, Deparment of Metallurgical and Materials Engineering, Ankara, Turkey, \\ ORCID ID orcid.org/0000-0002-3397-0201 \\ ${ }^{3}$ Gazi University, Faculty of Technology, Deparment of Metallurgical and Materials Engineering, Ankara, Turkey,
} ORCID ID orcid.org/0000-0003-4430-9360

\section{ARTICLE INFO \\ Article history: \\ Received 7 April 2020 \\ Received in revised form 11 June 2020 \\ Accepted 22 June 2020 \\ Available online 29 June 2020 \\ Research Article \\ DOI: $10.30728 /$ boron.715761 \\ Keywords: \\ Boron content, \\ Carbide/Boride morphology, \\ Effect of boron on high chromium steel, \\ High boron steel.}

\begin{abstract}
This study summarizes research into the effect of high boron additions on the microstructure of cast steel under the certain carbon $(0.42 \mathrm{C}$ wt. \%) and chromium (11.65 $\mathrm{Cr}$ wt.\%) content. Varying amounts of boron between $0.48-4.75$ wt.\% was added into steel melt. The boron analysis of the alloys was conducted by wet chemical analysis. The microstructure of the specimens was characterized with optical microscope, Scanning Electron Microscope with Energy Dispersive X-Ray Analysis (SEM/EDX) and X-Ray Diffraction (X-RD). The experimental results showed that high boron steel was successfully produced by sand casting with high casting yield. The microstructure of boron alloyed high chromium cast steel consists of three dimensional networks of $\mathrm{M}_{2} \mathrm{~B}$ borides surrounding the martensitic matrix in as cast condition. Under the certain carbon and chromium content, boron carbide volume fraction is directly depended on the boron additions. Due to the high amount of chromium and boron, carbides and borides were embedded in each other in all additions. In the specimens having less than $2.44 \mathrm{~B}$ wt.\%, carbide/boride structure was fishbone type with dendritic distribution over the matrix whereas rod/needle like structure with randomly distribute was observed in specimens having $2.44-4.75 \mathrm{~B}$ wt. \%. In all specimens containing boron, $\mathrm{M}_{2} \mathrm{~B}$ and $\mathrm{M}_{7}(\mathrm{C}, \mathrm{B})_{5}$ type carbides/boride peaks were detected by $\mathrm{X}-\mathrm{RD}$ analysis.
\end{abstract}

\section{Introduction}

High strength, hardness and wear resistant steels are studied and used since their invention. During their service life, they are used to process materials and withstand harsh tribological loads without compromising their performance. In order to achieve this, steels are improved by the dispersed carbides on the tempered martensitic matrix. However due to their advanced manufacturing technology and the necessity for alloying elements make them expensive [1,2].

Because of the shortage of alloying elements in World War II, scientists used boron in order to achieve desired mechanical properties in steels [3]. It has been found that with the little additions of boron between $0.001-0.003$ wt. $\%$, the hardenability of the steel increased which was having the same effect of $0.6 \mathrm{Mn}$ wt.\%, 0.7 Cr wt.\%, 0.5 Mo wt.\% or $1.5 \mathrm{Ni}$ wt.\% added steels [3-5]. The hardenability mechanism can be explained by the slowing down the nucleation of proeutectoid ferrite on the austenite grain boundaries by reducing the energy of the interface between adjacent austenite grains $[3,4,6]$.
In addition to hardenability, boron is strong carbide former. With its good combination of properties, such as; high hardness (29.1 GPa), low density (2.52 g.cm $\left.{ }^{-3}\right)$, high melting point $\left(2450^{\circ} \mathrm{C}\right)$ and high elastic modulus (448 GPa) makes boron carbide suitable for high temperature and high wear resistant applications [7].

Scientists mostly studied on the addition of the low boron wt.\%, mostly parts per million (ppm) levels in steels. There are a few researches that studied high boron steels. Egorov and Sapozhnikov investigated the effect of high boron additions (4.9-5.1 wt.\%) on the microstructure of cast steel having $0.15-1.2$ wt. $\%$ carbon contents [8]. They have reported that by increasing the carbon content in cast steel; chromium containing boride and carbon-boride phases formed, small microhardness change is also mentioned due to structural change. The wear resistance of high boron (1.18-3.0 wt.\%) steels was examined by Hanguang et al. [9-11]. According to their findings; boride networks were found out on top of metallic matrix of the cast steel. By increasing the quenching temperature, mechanical properties such as hardness, tensile strength 
is enhanced which was provided by the microstructural change. Lentz and Röttger carried out the solidification and phase formation of high boron (0.23-2.02 wt.\%) steels $[12,13]$. They have provided that by increasing the boron content, solidification sequence is also changed. In these scientific papers, valuable information about mostly wear properties and the matrix microstructures are discussed. However the morphology of carbides and borides need to be studied further.

The aim of this study is to investigate the microstructure of high boron alloyed of cast steel under the certain carbon (0.42 C wt.\%) and chromium (11.65 Cr wt. \%) content.

\section{Materials and methods}

The cast steel manufactured by melting of AISI 430 type of steel scraps in a $500 \mathrm{~kg}$ induction furnace with charge materials of ferrosilicon, ferromanganese, ferromolybdenum, graphite etc. In order to achieve desired chemical composition, deoxidation of melt was performed by using aluminum wire. Different amounts of calculated ferro-boron (0.5 - $5.0 \mathrm{wt} \%$ ) was added into melt at $1550{ }^{\circ} \mathrm{C}$ superheat and then poured into sand moulds of Y blocks (DIN 1683 - GTB 18/5). Chemical composition of alloy was determined by spectrometer (Bruker Q4-Tasman) which is given in Table 1.

$Y$ blocks were prepared for electrical discharge machining (EDM) by milling. All sides of $Y$ blocks were cleaned (2 $\mathrm{mm}$ depth). The metallographic samples were cut from bottom parts of the $Y$ blocks by EDM

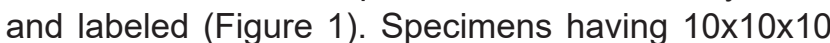
$\mathrm{mm}$ dimensions were prepared by grinding and polished up to $1 \mu \mathrm{m}$ diamond paste.

The boron analysis of the alloys was conducted by wet chemical analysis; Inductively Coupled Plasma Optical Emission Spectrometry (Perkin Elmer Optima 4300DV). Powder - chip mixture was liquefied in acid solution and analyzed by ICP-OES.

The microstructure of the specimens were analyzed by using Optical Microscope (Leica DM 4000 M) and Scanning Electron Microscope with Energy Dispersive X-Ray Analysis (Jeol JEM 6060 LV - SEM/EDX) after etching with Ralph solution [14].

Carbide/Boride distribution was determined by Leica DM 4000 M phase analyst. Specimen preparations and carbide/boride volume fraction calculations were conducted according to ASTM E1245 - 03 [15]. X-ray diffraction (XRD) analysis was performed on D8 DISCOVER $\mu \mathrm{MR}$ diffractometer with Copper Ka radiation coupling continuous scanning at $40 \mathrm{kV}$ and $40 \mathrm{~mA}$ as an X-Ray source in order to determine type of carbides/ borides in microstructure. Specimens were scanned in the $2 \theta^{\circ}$ ranging from $20^{\circ}$ to $80^{\circ}$ with scanning speed of $2 \%$ min and step space of $0.02^{\circ}$.

Table 1. Chemical composition of cast steel alloy.

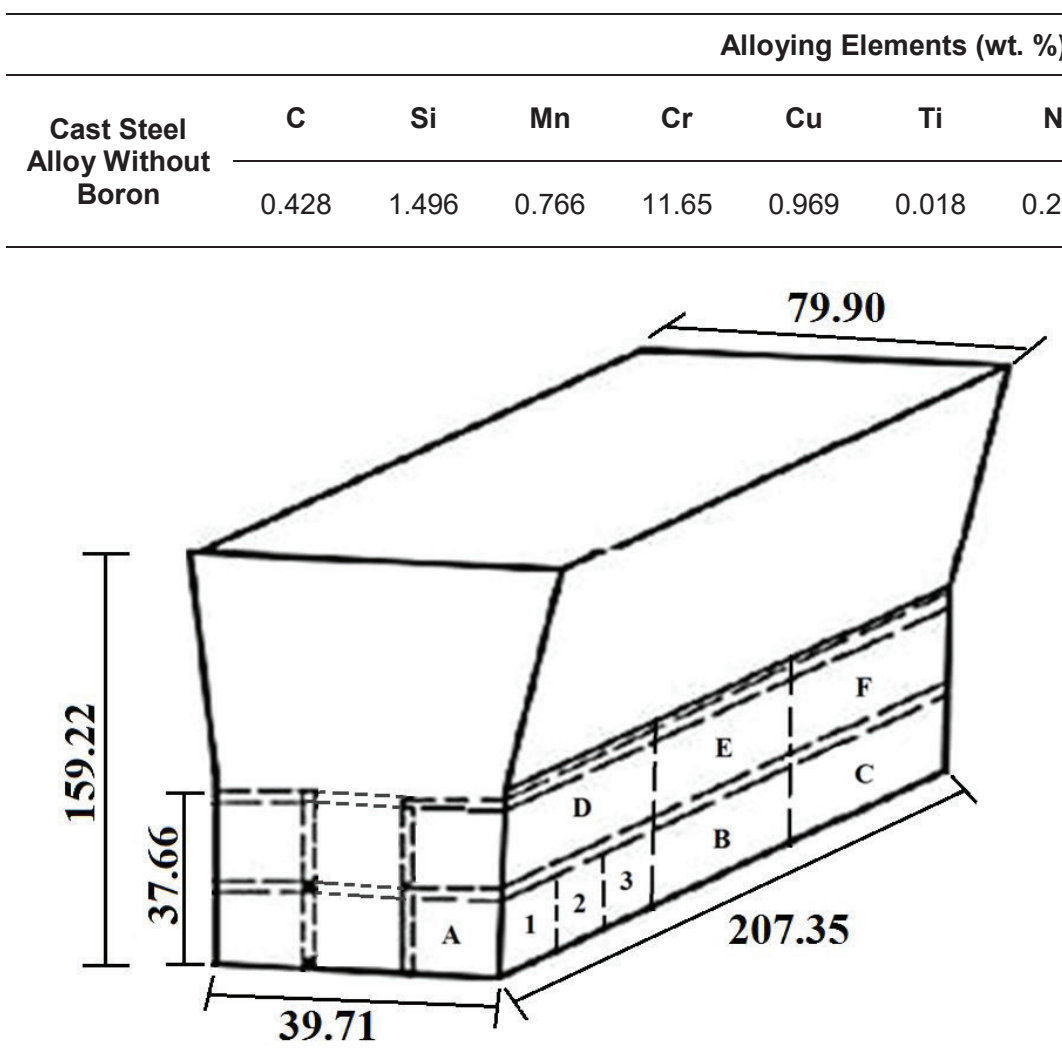

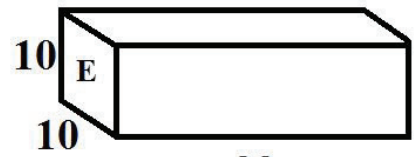

33

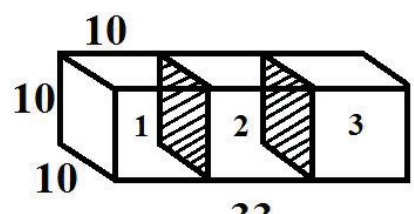

33

Figure 1. Sampling and labeling sequence of $Y$ block. 


\section{Results and discussion}

\subsection{Boron analysis of alloys}

The results of wet chemical boron analysis are given in Table 2. When considered the high affinity of boron on oxygen and nitrogen [3], non laboratory casting conditions and finally human factors, the casting yield was higher than expected (Table 2).

\subsection{Microstructure of alloys}

The microstructures of high boron alloyed steel alloy under the certain carbon ( $0.42 \mathrm{C}$ wt. \%) and chromium $(11.65 \mathrm{Cr}$ wt.\%) content are given in Figure 2 and Figure 3 in as cast condition. The microstructure of steel alloy without boron addition consists of a martensitic matrix and interdendritic eutectic chromium carbides, (Figure $2 \mathrm{a}$, highlighted green). Due to the high amount of alloying elements (11.65 Cr wt.\%, $1.496 \mathrm{Si} w t . \%$, etc.) martensitic matrix is expected upon cooling to the room temperature.

The experimental results indicate that boron between 0.48 - 2.05 wt. \% alloyed cast steel comprises eutectic borides and carbides having a dendritic network shape on the grain boundaries, (Figure $2 \mathrm{~b}-\mathrm{e}$, highlighted red). In addition, fishbone shaped carbide/borides are also formed (Figure $3 \mathrm{~b}$-e, red areas). However, when the boron weight percentage increases more than $2.05 \mathrm{wt} . \%$, rod/needle like carbide/borides are formed and randomly distributed over the matrix (Figure $2 \mathrm{f}$-h, highlighted blue, Figure $3 \mathrm{f}$-h highlighted yellow). The thickness and volume fraction of carbide/borides also increases with increasing boron concentration (Figure $2 \mathrm{~g}-\mathrm{h}$ and Figure $3 \mathrm{~g}-\mathrm{h}$ ). The transition between specimens having $2.05 \mathrm{~B}$ wt.\% to $2.44 \mathrm{~B}$ wt.\% is obvious,

Table 2. Boron analysis of the specimens.

\begin{tabular}{cccc}
\hline Specimen \# & Calculated Boron (wt.\%) & Boron Analysis (wt.\%) & Casting Yield (\%) \\
\hline I & - & - & - \\
II & 0.5 & $0.48 \pm 0.01$ & 96 \\
III & 1.0 & $1.12 \pm 0.01$ & 112 \\
IV & 1.5 & $1.18 \pm 0.01$ & 78,7 \\
V & 2.0 & $2.05 \pm 0.02$ & 102,5 \\
VI & 3.0 & $2.44 \pm 0.03$ & 81,3 \\
VII & 4.0 & $3.10 \pm 0.03$ & 77,5 \\
VIII & 5.0 & $4.75 \pm 0.10$ & 95 \\
\hline
\end{tabular}

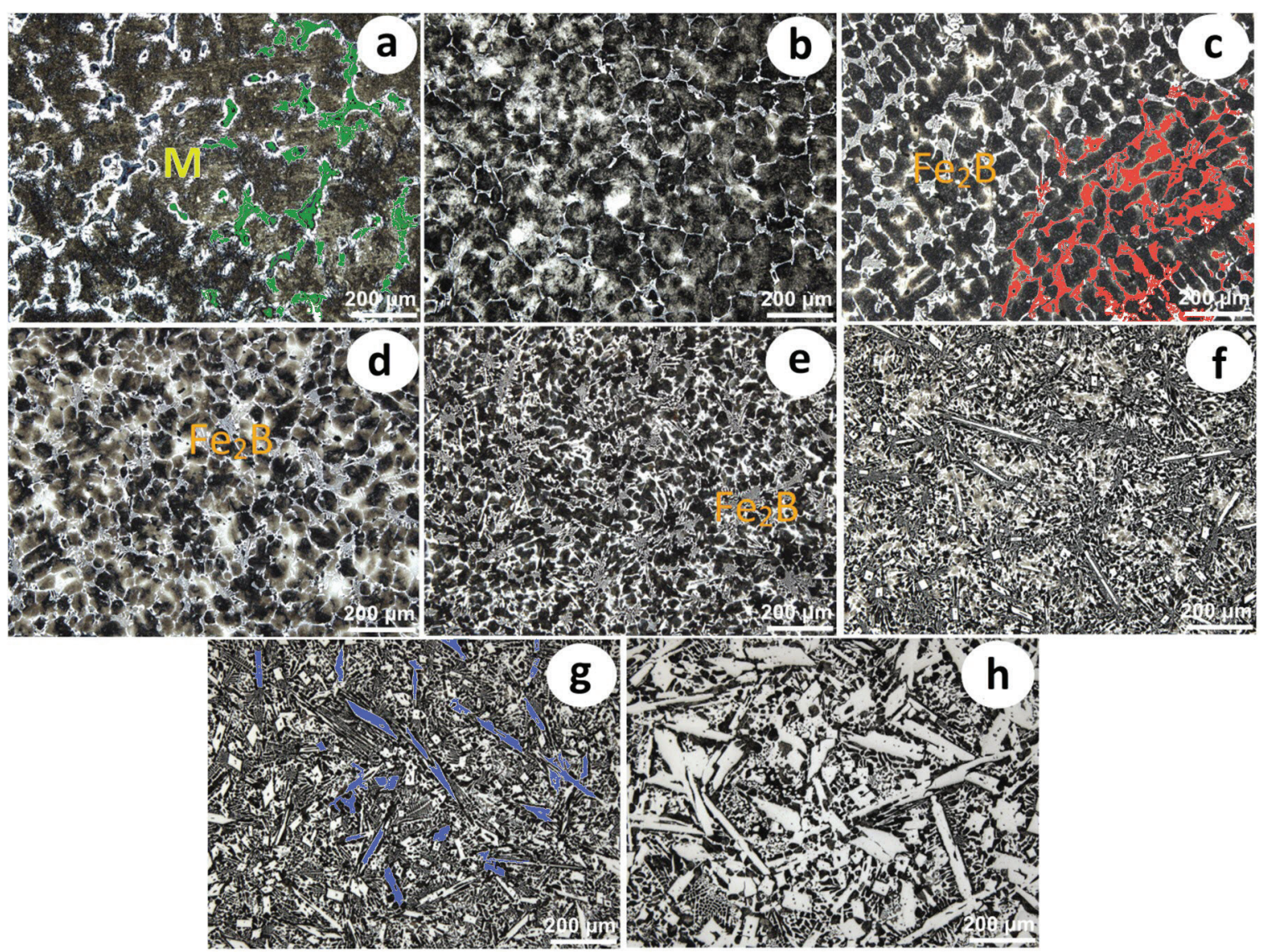

Figure 2. Microstructures of boron alloyed high chromium steel, a) Without B, b) 0.48 B wt. \%, c) 1.12 B wt. \%, d) 1.18 B wt. \%, e) 2.05 B wt. \%, f) 2.44 B wt.\%, g) 3.10 B wt.\%, h) 4.75 B wt.\%, M: Martensite, Etchant: Ralph, specimens cut from E-2 Y block sections. 

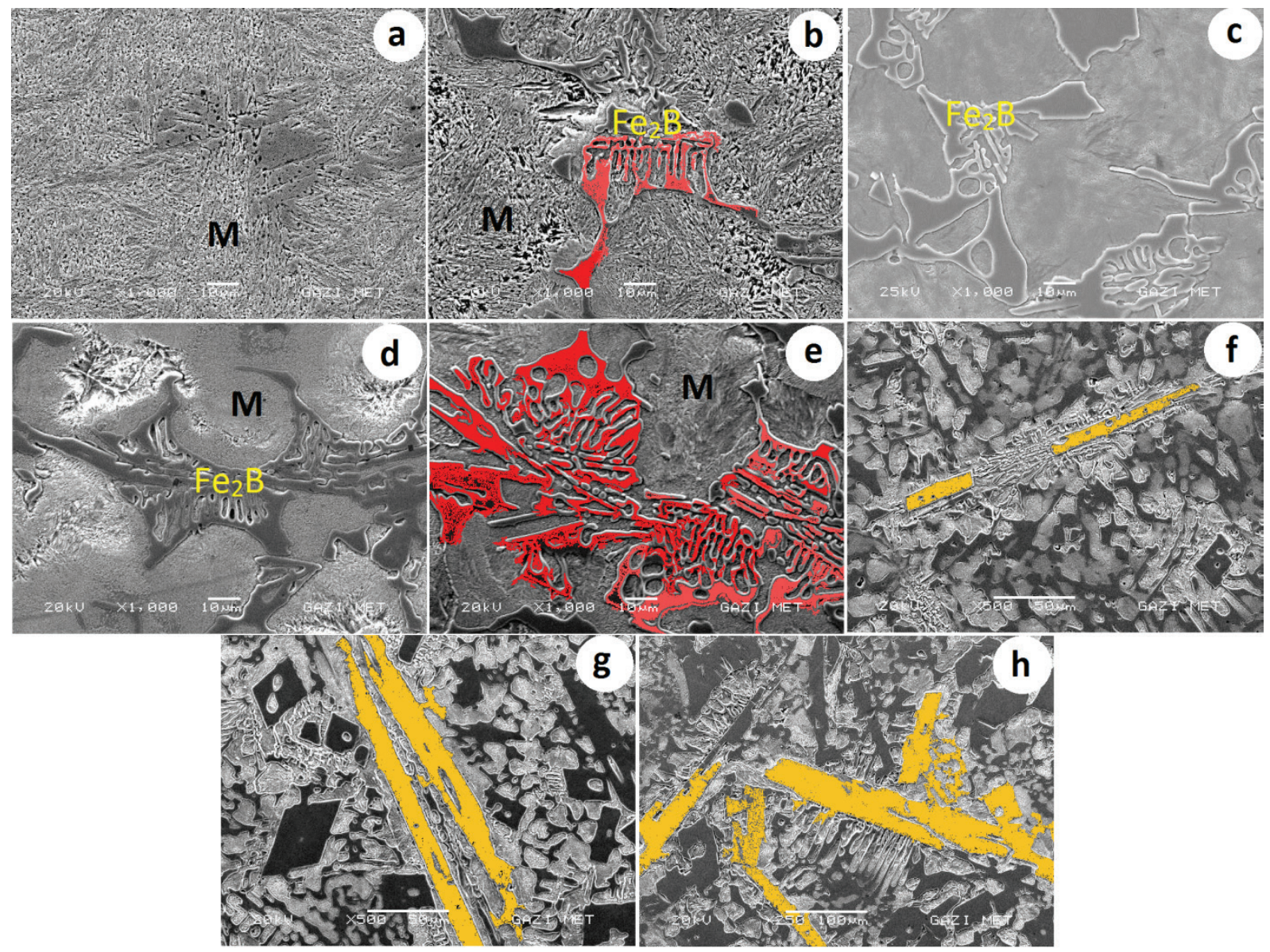

Figure 3. Carbide/Boride shapes of boron alloyed high chromium steel, a) Without B, b) 0.48 B wt.\%, c) 1.12 B wt.\%, d) 1.18 B wt.\%, e) 2.05 B wt.\%, f) 2.44 B wt.\%, g) 3.10 B wt.\%, h) 4.75 B wt.\%, M: Martensite, Etchant: Ralph, specimens cut from E-2 Y block sections.

however according to findings there is not an obvious change after $3.10 \mathrm{~B}$ wt.\% addition. The only change was the boride/carbide thickening that was mentioned above. In addition, boron additions did not alter the matrix; it remained same as seen in boron free sample which is martensitic.

Many researchers were also observed martenstic matrix and interdendritic eutectic carbides which constitute a three-dimensional networks surrounding the matrix in the microstructure of high boron cast alloys $[8,9,16-18]$. Zhang et. al. pointed out that the matrix is mainly martensite and with small amount of austenite in the microstructure of boron free cast steel alloy [17]. The concentration of 0.4 wt. \% boron in the $\mathrm{Fe}-\mathrm{Cr}-\mathrm{B}$ alloy resulted in eutectic phase of network structure at the grain boundary, and when compared with boron free sample, matrix is not changed. As boron concentration increases, the amount of the eutectic phase increases with distribution along the grain boundary. They also reported that the formation of $\mathrm{Fe}_{2} \mathrm{~B}$ and $(\mathrm{Cr}$, $\mathrm{Fe})_{7}(\mathrm{C}, \mathrm{B})_{3}$ phase increases with increasing boron concentration [17].

Egorov and Sapozhnikov were obtained randomly distributed, thick rod/needle type carbides/borides in the alloy having $0.39 \mathrm{C}$ wt.\%, 5.0 B wt.\% [8]. Sude Ma

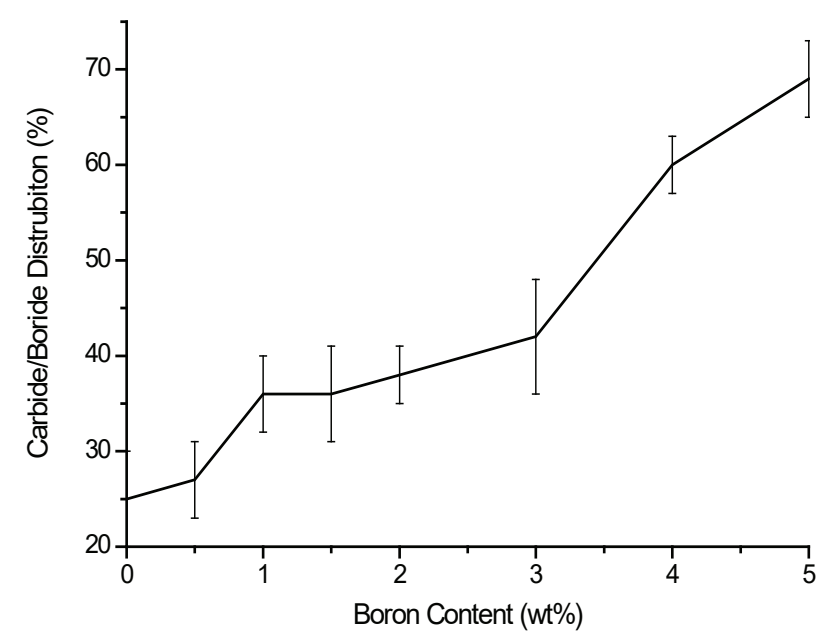

Figure 4. The relation between carbide/boride distributions with respect to boron content.

and Jianjun Zhang explained that the solidification of Fe-Cr-B alloy produced a dendritic matrix and interdendritic $\mathrm{M}_{2} \mathrm{~B}$ borides, which constitute a three-dimensional networks surrounding the dendritic matrix [18]. Zhuang et. al. illustrated four different carbide/boride shapes on their samples [19]. The result of obtained carbide/boride shapes in the microstructure of high boron steel alloy is in good agreement in the studies by Egorov and Sapozhnikov [8] and Zhuang et. al [18]. 


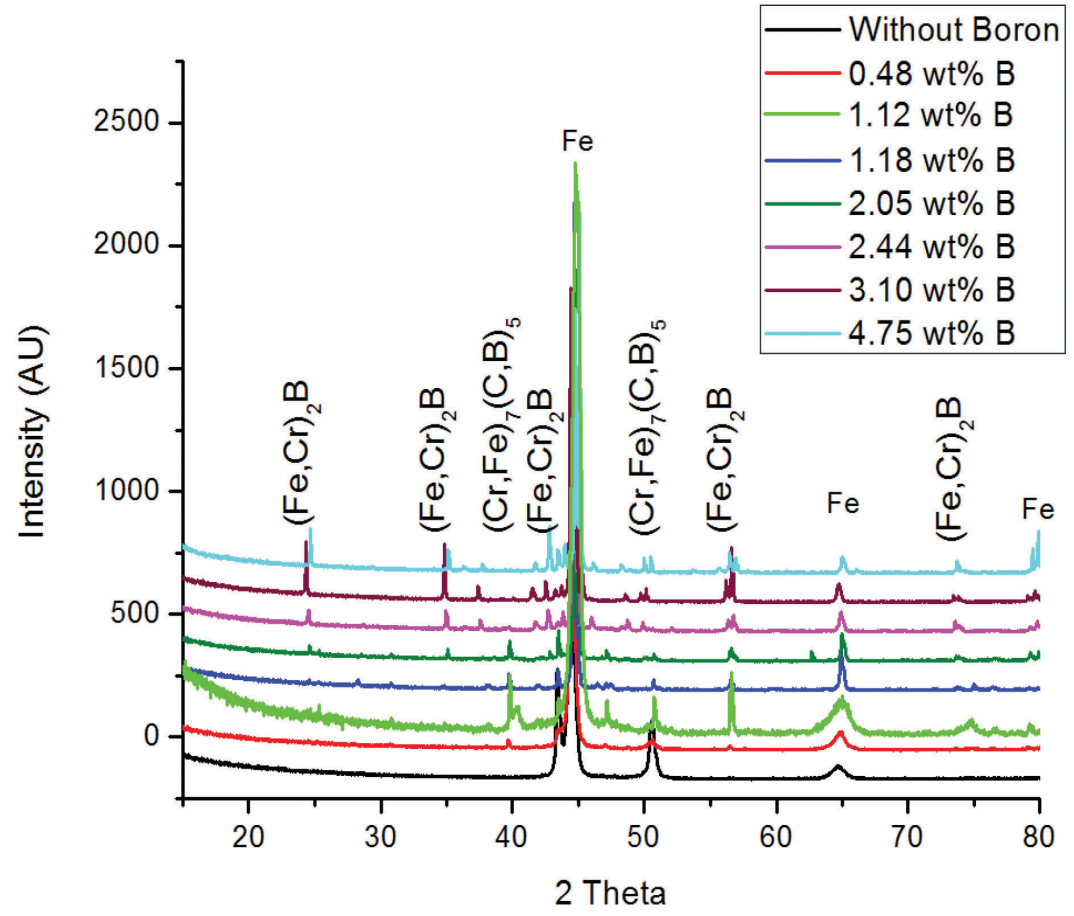

Figure 5. X-RD analysis of the cast steel with different boron content.

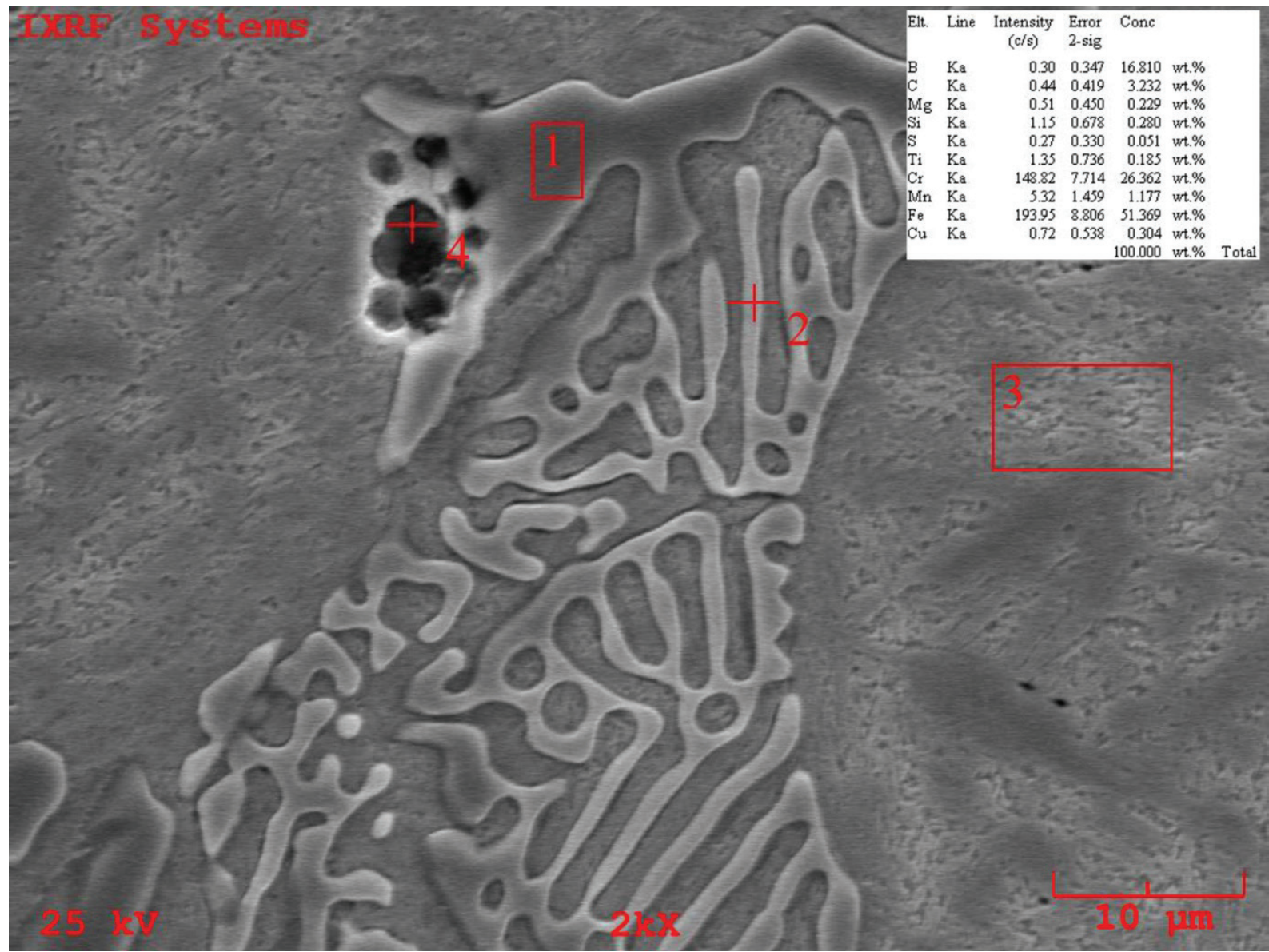

Figure 6. EDS analysis of boron alloyed high chromium steel having $1.12 \mathrm{~B}$ wt.\%.

In the high boron alloyed of cast steel under the certain carbon (0.42 C wt.\%) and chromium (11.65 Cr wt.\%) content boron carbide volume fraction is given in Figure 4. It is shown that boron carbide volume fraction increases with increasing the boron content expected. The carbides and borides embedded in each other; hence it was not possible to differentiate by X-RD. 
$\mathrm{X}-\mathrm{RD}$ analysis result of the specimens is given in Figure 5 . In free boron sample, $M_{7} C_{5}$ type chrome carbides were identified ( $\mathrm{M}$ : $\mathrm{Fe}, \mathrm{Cr}$ ). In all specimens containing boron, $M_{2} B$ and $M_{7}(C, B)_{5}$ type carbides/boride peaks were detected. Some researchers [16,20,21] detected similar carbide/boride types on the specimens having identical chemical composition under the equivalent $X-R D$ parameters $\left(2 \theta^{\circ}\right.$, Copper Ka radiation). It is known that EDX analysis is not recommended in detecting boron [22]. In order to differentiate carbides from borides, EDX analysis performed nonetheless. However, carbides and borides could not be separated due to chrome carbides and borides that were embedded in each other. This is confirmed by SEM/EDX analysis on as cast specimen having 1.12 B wt.\%, (Figure 6, point 1). Table 3 identifies the points from Figure 6.

Table 3. Identification EDS analysis points from Figure 6.

\begin{tabular}{cc}
\hline Point & Structure \\
\hline 1 & $\mathrm{Fe}_{2} \mathrm{~B}+$ Chrome Carbide Mixture \\
2 & $\mathrm{Fe}_{2} \mathrm{~B}+$ Chrome Carbide Mixture \\
3 & Martensitic Matrix \\
4 & Carbide/Boride Mixture \\
\hline
\end{tabular}

\section{Conclusions}

The main conclusion deduced from this work on the investigation of the microstructure of high boron alloyed cast steel under the certain carbon (0.42 C wt.\%) and chromium (11.65 $\mathrm{Cr}$ wt.\%) content may be summarized as follows:

- Knowing the strong affinity of boron on oxygen and nitrogen, high boron (0.48-4.75 wt.\%) alloyed cast steel under the certain carbon (0.42 C wt.\%) and chromium (11.65 Cr wt.\%) content was successfully manufactured with high casting yield.

- Specimen without boron consists of martensitic matrix with chromium carbides network. Small amounts of boron additions (up to $2.05 \mathrm{~B}$ wt.\%) created borides combined with existed carbides. The boron additions formed fishbone carbide/borides and changed their distribution to dendritic network.

- $\quad$ On alloys having higher boron percentages (2.44 - 4.75 wt. \%) fishbone shape and dendiritc network distribution were modified to new form of rod/need like carbide/borides that are randomly distributed over the matrix.

- $\quad$ By increasing the boron content (2.44 - 4.75 wt.\%), carbide/boride volume fraction increased. There is almost no visible change other than carbide/ boride coarsening between the boron content of 3.10 - 4.75 wt.\%. Boron additions did not modify the martensitic matrix, it remained unchanged.
Carbides and borides were embedded in each other. In all specimens containing boron, $\mathrm{M}_{2} \mathrm{~B}$ and $M_{7}(C, B)_{5}$ type carbides/boride peaks were detected.

\section{Acknowledgments}

The authors appreciate the financial support from the Gazi University Projects of Scientific Investigation (BAP) within the project "07/2018-06". The authors are grateful to Middle East Technical University (METU) for ICP-OES analysis.

\section{References}

[1] Krauss G. Steels: processing, structure, and performance, Asm International, 2015.

[2] Bhadeshia H., Honeycombe R. Steels: microstructure and properties, Butterworth-Heinemann, 2017.

[3] Banerji S. K., Morral J. E., Boron in Steel, Milwaukee, Wis, 18 Sept. 1979.1980, 1979.

[4] Davis J. R., Mills K. M., Lampman S. R., Metals handbook. Vol. 1. Properties and selection: Irons, steels, and high-performance alloys, ASM International, Materials Park, Ohio 44073, USA, 1990.1063, 1990.

[5] Llewellyn D. T., Cook W. T. Metallurgy of boron-treated low-alloy steels, Metals Tech., 1 (1), 517-529, 1974.

[6] Hwang B., Suh D. W., Kim, S. J. Austenitizing temperature and hardenability of low-carbon boron steels, Scr. Mater., 64 (12), 1118-1120, 2011.

[7] Suri A. K., Subramanian C., Sonber J. K., Murthy T. C. Synthesis and consolidation of boron carbide: A review, Int. Mater. Rev., 55 (1), 4-40, 2010.

[8] Egorov M. D., Sapozhnikov Y. L., Shakhnazarov Y. V., Effect of carbon content on the structure, hardness, and thermal stability of boron-chromium cast steels, Met. Sci. Heat Treat., 31 (5), 387-391, 1989.

[9] Fu H. G., Xing,J. D., Lei,Y. P., Huang, L. M., A Study on the wear behavior of cast boron steel, J. Mater. Eng. Perform., 20 (9), 1665-1670, 2011.

[10] Fu H. G., Wu Z. W., Xing, J. D. Investigation of quenching effect on mechanical property and abrasive wear behaviour of high boron cast steel, Mater. Sci. Technol., 23 (4), 460-465, 2007.

[11] Fu H. G., Fu D. M., Xing J. D. Investigations on the cast boron steel guide roller and its application in steel wire-rod mill, Mater. Manuf. Processes, 23 (2), 123129, 2008.

[12] Röttger A., Lentz J., Theisen, W., Boron-alloyed Fe$\mathrm{Cr}-\mathrm{C}-\mathrm{B}$ tool steels-Thermodynamic calculations and experimental validation, Mater. Des., 88, 420-429, 2015.

[13] Lentz J., Röttger A., Theisen W., Solidification and phase formation of alloys in the hypoeutectic region of the Fe-C-B system, Mater., 99, 119-129, 2015.

[14] Standard A. S. T. M., E407-07: Standard Practice for Microetching Metals and Alloys. ASTM International., West Conshohocken, PA, 2012. 
[15] Standard A., ASTM E 1245-03: Standard Practice for Determining the Inclusion or Second-Phase Constituent Content of Metals by Automatic Image Analysis, Annual Book of ASTM Standards, 3, 1-8, 2012.

[16] Zhang J., Gao Y., Xing J., Ma S., Yi D., Yan J., Effects of chromium addition on microstructure and abrasion resistance of Fe-B cast alloy, Tribol. Lett., 44 (1), 31, 2011.

[17 ] Zhang H., Fu H., Jiang Y., Guo H., Lei Y., Zhou R., Cen Q., Effect of boron concentration on the solidification microstructure and properties of Fe-Cr-B alloy, Materialwiss. Werkstofftech., 42 (8), 765-770, 2011.

[18] Ma S., Zhang,J., Wear resistant high boron cast alloya review, Rev. Adv. Mater. Sci, 44, 54-62, 2016.
[19] Zhuang M., Li M., Wang J., Ma Z., Yuan S., Study on composition, microstructure and wear behavior of $\mathrm{Fe}$ $\mathrm{BC}$ wear-resistant surfacing alloys, J. Mater. Eng. Perform., 26 (12), 6182-6192, 2017.

[20] Ma S., Xing J., Liu G., Yi D., Fu H., Zhang J., Li Y., Effect of chromium concentration on microstructure and properties of Fe-3.5 B alloy, Mater. Sci. Eng. A, 527 (26), 6800-6808, 2010.

[21] Guo C., Kelly P. M., Boron solubility in Fe-Cr-B cast irons, Mater. Sci. Eng. A, 352 (1), 40-45, 2003.

[22] Banerji S. K., Morral J. E., Boron in Steel. Milwaukee, Wis, 18 Sept. 1979, 1980, 1979. 